\title{
COGNITIVE ASPECTS OF COLLABORATION IN 3D VIRTUAL ENVIRONMENTS
}

\author{
V. Juřík ${ }^{a}{ }^{*}$, L. Herman ${ }^{b}$, P. Kubíček ${ }^{b}$, Z. Stachoň ${ }^{b}$, Č. Šašinka ${ }^{a}$ \\ ${ }^{a}$ Department of Psychology, Faculty of Arts, Masaryk University, Arna Nováka 1/1, 60200 Brno, Czech Republic - \\ jurik.vojtech@gmail.com, 44276@mail.muni.cz \\ ${ }^{\mathrm{b}}$ Department of Geography, Faculty of Science, Masaryk University, Kotlářská 2, 60200 Brno, Czech Republic - \\ herman.lu@mail.muni.cz,kubicek@geogr.muni.cz,14463@sci.muni.cz \\ * corresponding author
}

ThS16: Perceptual and cognitive experiments with imagery and 3D models

KEY WORDS: 3D visualization, decision making, human-machine interaction, MUVE, presence, situation awareness virtual collaboration, virtual environments.

\begin{abstract}
:
Human-computer interaction has entered the 3D era. The most important models representing spatial information - maps - are transferred into 3D versions regarding the specific content to be displayed. Virtual worlds (VW) become promising area of interest because of possibility to dynamically modify content and multi-user cooperation when solving tasks regardless to physical presence. They can be used for sharing and elaborating information via virtual images or avatars. Attractiveness of VWs is emphasized also by possibility to measure operators' actions and complex strategies. Collaboration in 3D environments is the crucial issue in many areas where the visualizations are important for the group cooperation. Within the specific 3D user interface the operators' ability to manipulate the displayed content is explored regarding such phenomena as situation awareness, cognitive workload and human error. For such purpose, the VWs offer a great number of tools for measuring the operators' responses as recording virtual movement or spots of interest in the visual field. Study focuses on the methodological issues of measuring the usability of 3D VWs and comparing them with the existing principles of 2D maps. We explore operators' strategies to reach and interpret information regarding the specific type of visualization and different level of immersion.
\end{abstract}

\section{INTRODUCTION}

Virtual visualizations have entered the 3D era (Boughzala et al., 2012). External graphical representations of the space - maps - are often transformed into interactive virtual 3D versions with respect to the specific content to be displayed and as such they can be dynamically modified, updated and customized. Regarding the evidence of using interactive 3D maps in many fields of applied areas as crisis management, army or aviation (Konecny, 2011; Stanek et al., 2010; Maggi et al., 2016; Lin et al., 2015), the relevance of the 3D maps as the base for the virtual environments increases.

Some researchers consider the virtual reality (VR) as the application of computer technologies to create interactive, 3 dimensional world, where the operator feels to be present (Bryson, 1999). The level of elaboration of 3D-visualisations tends to bring more visual/environmental fidelity (Hochmitz and Yuviler-Gavish, 2011). However, the tendency to increase fidelity or to increase feeling of presence in virtual environment can be ambiguous and may not directly enhance cognitive processes as remembering or making the correct decision (Mania et al., 2006) as well as not promote spatial orientation (Waller et al., 2001). Nevertheless, the immersive 3dimensional visualisations/environments are more and more used in such areas as crisis management (Bandrova et al., 2012; Reznik et al., 2013) or aviation and vehicular traffic, where every aspect of the interface has a huge impact on the human safety (Rierson, 2013; Zimmerman and Koebbe, 2013).

Levan (2004) defines cooperation (or collaboration) as a social activity that uses the knowledge, skills and efforts of a few individuals to achieve group goals, which could not be achieved by individuals working alone. The development of IT technologies instigated the possibilities of virtual collaboration (Boughzala et al., 2012). 3D virtual maps or other models of geographical space can represent the metaverses, where more operators are allowed to cooperate (collaborate) when solving specific task regardless to their physical presence (Davis et al., 2009). The every particular aspect of reality can be simulated in metaverses regarding the usability of such an environment. The virtual supportive platforms for the distanced learning are already now the common technology helping students and staff on many universities to keep in touch with the current class issues and promote class cooperation (Dalgarno et al., 2011; Petrakou, 2010).

From the simple forms of virtual spaces the development is heading to Multi-User Virtual Environments (MUVEs), where the importance of social, cooperative and communicational aspects of interaction are emphasized (Montoya et al., 2011; Dalgarno et al., 2011; Lim et al., 2006; Barab et al., 2005, Hideyuki, 2004). MUVEs, as a specific way of interface, can offer to users or operators more possibilities of real time interaction when solving particular task. They can be used for sharing and elaborating information and allow avatars to interact with each other and/or with software agents (Davis et al., 2009). Attractiveness of VWs is emphasized also by the possibility to control and precisely measure operators' responses in terms of specific actions, strategies and complex behaviour (Wilson and Soranzo, 2015). This attractiveness is emphasized also with the use of geographic models as the stimuli, where the amount of communicated information is precisely defined. 


\section{PSYCHOLOGICAL PERSPECTIVE ON INTERACTIVE 3D GEOGRAHICAL INTERFACES}

In MUVEs as well as in other types of 3D virtual environments the optimality of specific type of user interface (UI) is considered. What is the specific role of the selected method of $3 \mathrm{D}$ visualisation and particular interface settings is an issue for ongoing research. Within the area of Human factors, the use of different user interfaces was explored with respect to the users' performance and safety (Weinberg et al. 2011). The dominant issues of the research interest are represented by the concepts as situation awareness (Endsley, 1995) and cognitive workload. Mentioned concepts provide simple correlation: the more information is communicated to help user, the higher risk of the cognitive workload and human error may occur (Forsell, 2007; Tavanti et al., 2003; Lange, 2003). From this point of view, Hammond and Stewart (2001) discuss the issue of proximal cues playing role in decision-making. In specific informationally equivalent interfaces there can be some proximal cues prioritized to others, which can affect the human behaviour. In some applied areas as crisis management, aviation etc. this issue is crucial for the human life or property safety.

The Neisser's (1976) perception cycle emphasizes the sensorimotor nature of cognition by highlighting anticipatory schemata as the two-ways modifiable structures affecting the process of searching for information in the environment. In coherence with Brunswik's theory (Hammond and Stewart, 2001) the perception is considered as the cyclic activity based on the active motor action of observer. Cyclically, based on the incoming visual information, the motor activity is further concentrated on the specific objects in the visual field. The nature of the environment-based sensorimotor process is studied also with respect to the human error making (Plant and Stanton, 2012). Assumptions about motor aspects of perception is emphasized also in the embodied cognition approach (Wilson, 2002; Anderson, 2003), where the bodily elaborated information has different quality than visually communicated information (Meteyard et al., 2012). The evaluation of interactive nature of immersive $3 \mathrm{D}$ visualization is therefore actual issue.

Presence in VR (Mania et al., 2006; Björk and Holopainen, 2004; Mania and Chalmers, 2001; Slater and Wilbur, 1997), or also immersion, is the phenomena which could be explored with respect to media synchronicity theory. From this point of view it is suggested that effective collaboration technology (including specific interface or the type of visualisation) should improve the process by which people work together at the same time with a common focus. Media synchronicity theory speaks about improving users' collaboration when the synchronicity capacity of technology matches the needs of collaborators (Dennis et al., 2008). Hassell and Limayem (2010) found presence playing important role in the motivation of VR users, which is further affecting positive relationship between media synchronicity and job satisfaction. The presence or "the feeling of being there", was found important for the effectivity of learning in VR also by Bailenson et al. (2006).

Other studies mention that the so-called engagement (Bakker et al., 2011), which means the involvement of users into VR, is a crucial aspect when focusing on task-solving. Bakker et al. (2011) as well as earlier Hossain and Wigand (2004) argue that within VR issues the engagement is the predeterminant of the state flow (Csikszentmihalyi, 1990). Flow is a strong effector of how the users interact with specific user interface (UI) and thus of their overall performance when working in VR. Further, Goel and Prokopec (2009) speak also about social aspects of interaction in VR.

For the design of the virtual collaborative space it is necessary to consider particular purpose of the interface. The specific version of MUVEs, Collaborative Virtual Learning Environment (CVLE), represents the virtual space, where operators are allowed to communicate and cooperate via text, pictures and videos or directly by virtual 3D avatars representing them in the VR with the learning purposes (Biocca et al., 2003). CVLEs are expected to improve and support the process of learning (Barab, et al., 2005; Hideyuki, 2004; Lim et al., 2006; Montoya et al., 2011; Johnson et al., 2002). Ibáñez et al. (2013) deal with the issue of the communication effectivity and workflow in VR collaborative learning, where the necessity of active group cooperation, communication and discussion is suggested as a promoter of effective learning. The aspects of collaboration can be analysed from more than one point of view and can be also compared to collaboration in real environment (Riedl et al., 2014; Greiner et al., 2014).

\section{INFLUENCE OF CARTOGRAPHIC VISUALIZATION METHODS ON MENTAL REPRESENTATION}

Information science offers concepts that are closely related to collaboration via VR. According to Shuman (1992), information science examines properties and conduct of information, their transfer and optimization of possibilities of this transmission between the natural and artificial systems, and the influence of information on the behaviour (feedback) of people and/or machines. The process of transferring information through the map language was described e. g. by Kolacny (1968) in the theory of cartographic communication (Fig. 1), who emphasized the information shift of the depicted content due to the different understanding of the real-world phenomena on the side of a cartographer and then also on the side of a map reader. This shift can also be caused by the different form of depiction, e. g. excessive simplification.

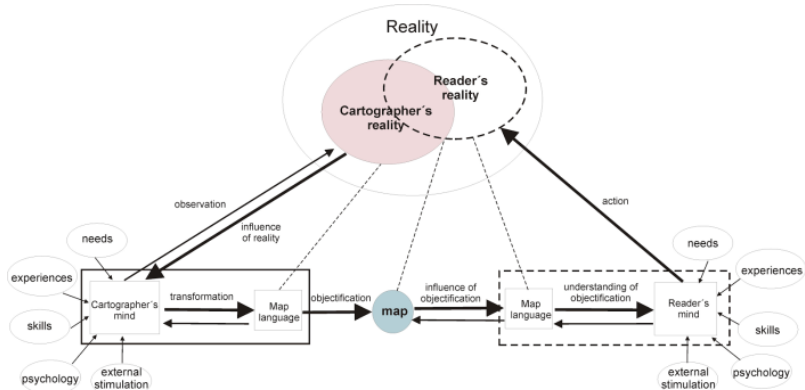

Fig. 1. Schema of cartographic communication (adapted from Kolacny, 1968)

Development of 3D cartographic visualization is always conditioned by the development and availability of contemporary hardware and software accessories. MacEachren and Kraak (2001) define the tasks which should be the subject for the further research and development in this area, including research of new technologies, finding the limits and suggesting a new design of cartographic visualization methods. These targets should be accomplished by the research of the impact of such technologies on the user (and on his performance when using a new technology). 


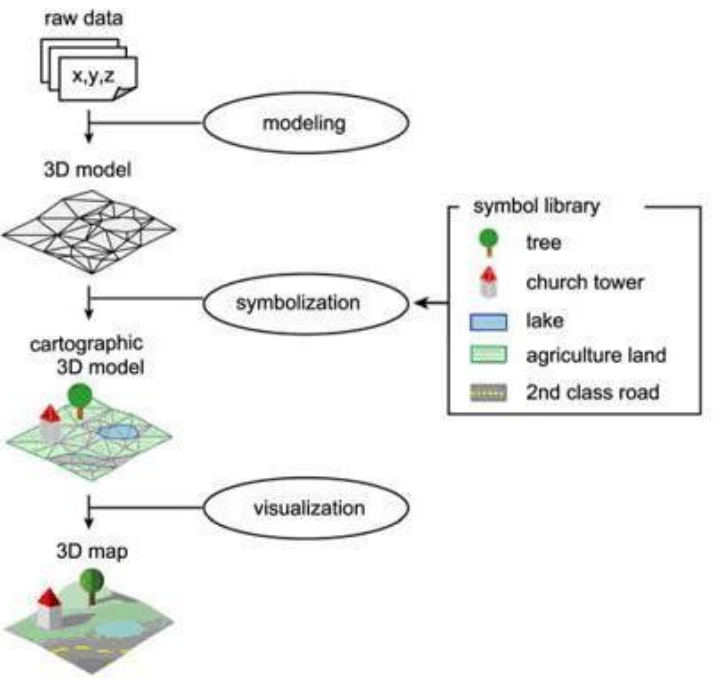

Fig. 2. Schematic process of creating 3D maps (Häberling et al., 2008)

Cartographic 3D visualizations are usually generated from the 3D data models by symbolizing the individual objects (Fig. 2). The 3D visualization method is influenced not only by cartographic generalization which is contained in the 3D data model, but also by the level of abstraction used for map objects. Objects in the process of symbolization are represented in addition to their position as well as through graphic variables (Bertin, 1967). In the case of 3D visualization, however, it is necessary to take into account also other graphic components, for example representation of terrain, lighting and angle of view of the 3D model. There is large variety of cartographic visualization methods suitable for $3 \mathrm{D}$ environment form realistic visualization (photorealistic rendering) to the abstract simplistic depiction which can be used to enhance specific type of objects and map elements essentially for solving of particular task (see Fig. 3). Functionality of selected cartographic visualization methods is also heavily influenced by the used UI. Users need to get the desired information quickly and correctly, so these aspects are considered as the most important attributes of all types of visualizations. Additionally this necessity could be also demanded legislatively (Reznik, 2013).
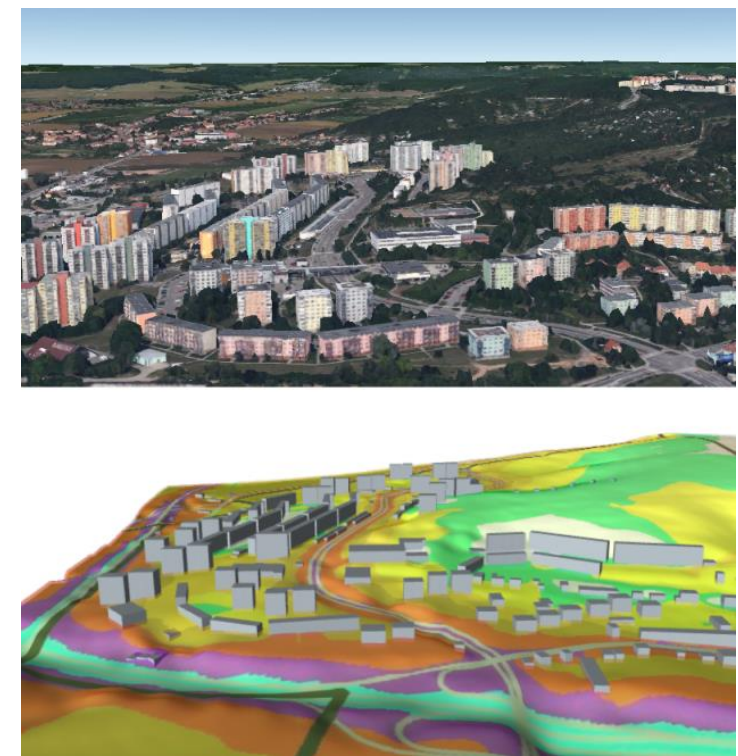

Fig. 3. Photorealistic visualization from Google Earth and abstract visualization of 3D noise map. Area of city district
Nový Lískovec (Brno, Czech Republic) is shown in both cases (adopted from Herman and Reznik, 2013)

\section{RESEARCH AIMS}

It is evident from the information mentioned above; understanding of collaboration in 3D virtual environments requires an interdisciplinary approach. Research platform CEPCoS (Center for Experimental Psychology and Cognitive Sciences, Faculty of Arts, Masaryk University) was established to fulfil this research purposes. CEPCoS associates experts from three workplaces of Masaryk University: Faculty of Arts, Faculty of Science and Faculty of Informatics. The interdisciplinary diversity allows us to focus on cross sections between cartography, geoinformatics, psychology and computer science. One of last-standing research interest deals with the evaluation of interactive maps and 3D virtual environments, for example we investigated the influence of type of specific cartographic visualization on the cognitive processing of spatial data in VR (Kubicek et al., 2014; Sprinarova et al. 2015; Herman and Reznik, 2015; Kubicek et al., 2016; Popelka et al., 2016).

The following research interests are dedicated to the collaboration in virtual spaces with the respect to the type of visualisation and specific interface affecting the process of learning, interaction and cooperation in VR. We also explore the influence of various UIs on the cognitive workload and situational awareness when using the same geographic model. We examine specific differences in the strategies of interactive manipulation with virtual geographical model. User specific strategies of interaction are considered to be important for cognitive processing of particular task when working independently/cooperatively in a real environment as well as cooperatively in a virtual environment.

\section{PERIPHERAL DEVICES ISSUE}

For the above mentioned research focus it is necessary to define user interface regarding the observed phenomena. In general, on one hand we should consider emulation of $3 \mathrm{D}$ visualization and on the other stands the technology securing interaction with UI control device.

\subsection{Current technologies for immersive visualization}

Contemporary technologies offer more ways to emulate 3D visualization. It is usually maintained by the use of the 3D glasses and a large format planar media (a monitor or a projection screen). Most of the 3D systems are based on the principle of filtering glasses, which split the observed exposition and provide slightly different images for each eye separately, to reach stereopsis. We can find active and nonactive 3D technologies, which allow us to distribute images of an exposition separately into a left and a right eye.

Within non-active 3D systems we can find anaglyph, Dolby 3D technology or glasses based on the principle of polarization (Roebuck, 2011). Active systems usually contain embedded active electronic component to provide distribution of slightly different image for each eye separately. Mainly we speak about active shutter 3D system which uses liquid crystal shutter glasses. The embedded electronic component conceal alternately right or left eyeglass in a very high speed. It presents the image for the left eye while blocking the view of the right 
eye and vice versa. This alternation enables user to read synchronized information for a corresponding eye on a projection screen. The synchronicity between glasses and the refresh rate of the projection screen is secured with a timing signal, via Bluetooth or another wireless technology, eventually wired signal. The frequency of the broadcasted content should be on the level of $120 \mathrm{~Hz}$ (60 images per second for each eye), so a specific kind of projection screen/monitor is needed (a 120 $\mathrm{Hz}$ display). (Roebuck, 2011)

The next step in 3D visualization constitute head-mounted displays (e.g. Oculus Rift) which can be placed on a user's face and expose binocularly images separately for the left and right eye. The value added to this technology is a detector of movement. Due to the movement detector, the user is able to look around in a virtual environment and so the level of fidelity and immersion is very high. Also it disposes with the addition of microphone and headphones into this device. The immersive simulations of a wide spectre of activities could be done with head-mounted displays. With a constantly improving level of computer graphics and the fact that the display is not bound to a static device, the possibilities of head-mounted displays for virtual simulations are almost unlimited. The promising future of this technology is unfortunately disturbed by users' frequent feelings of sickness while using it.

Such empirical evidence as e.g. an increased efficiency at performing 3D virtual navigation with the use of larger 3D displays opens a discussion on the level of the impact of situated and additive devices on human cognitive processes in practice (applied areas). In the geographical data displaying it is constituted the question in which way the type of visualization technology affects the user's performance on cognitive and behavioural level (Sprinarova et al., 2015).

\subsection{Technologies for Human-Computer Interaction}

Movement in a three-dimensional space can be based on different principles. All moves must be possible for all directions. The common computer interface is controlled by a regular computer mouse, which offers only two degrees of freedom (DoF) for the movement in the two-dimensional planar space. As suggested by Bowman et al. (2004), in 3D space should be used the device with more than two degrees of freedom. The satisfactory device or interface should allow the user to use 6 DoFs.

A 3D mouse is often used for a movement in 3D virtual spaces. The 3D mouse allows the movement in all six DOFs. A user can pan, zoom and rotate in all three axes (X, Y and $\mathrm{Z}$ ) and this can be performed simultaneously, all the movements' options are included in the device. The 3D mouse controller consists of a pressure-sensitive handle to move through 3D environments or interact with 3D models. Wii Remote Controller (Wii RC) was originally developed for the Nintendo's Wii console. This device disposes with motion sensing capability, which ensures user's ability to manipulate with exposition presented on a screen via gestures and pointing. In combination with the Kinect or the motion capture system, it can be used to control remote planar media expositions such as the visualizations on $3 \mathrm{D}$ projections screens.

Motion Capture system (MoCap) is tracking device which works on a mechanism of recording movement of reflective points in its visual field. The set of several cameras placed in the room calculate the position of reflexive points and record their current positions. Such a movement can be reproduced in an artificial environment and become a base for a digital animation/record. Moreover it can be used as a UI controller. In combination with a specific software and device it can be used to handle the exposition. Such a tracking devices is able to capture $\mathrm{x}, \mathrm{y}, \mathrm{z}$ positions in real time and also an orientation of user's body in reference to a fixed point.

\subsection{Monitoring of user's interaction and strategy}

As suggested above, the tracking of participant activity in the VR is the indispensable factor of human-computer interaction research. The Motion Capture system can measure the bodybased motoric activity of participants, but there are more devices used for the measuring participants behaviour within interactive virtual environments.

With respect to the specific type of visualization it is necessary to measure the precise spots of interests in the participant visual field. The virtual environment consists, as suggested above, of specific proximal cues (Hammond and Stewart, 2001), which relevance can be affected by the type of $3 \mathrm{D}$ visualization. To capture participants' spots of interest, the eye-tracking system can be used. Eye-tracking system constitutes the device recording the participant's eyes movement and links it with particular depicted object/screen position (Brychtova et al., 2012; Popelka and Vozenilek, 2013). Several Eye-tracking systems are contemporarily available. Mobile versions of Eyetracker are used to measure fields of interests of participant in real environment; static eye-tracking system is used to capture specific screen/monitor areas of interest. The value added is the potentiality to combine the eye-tracker system with the headmounted display and measure the perception activity within immersive VR.

The possibilities of use of neuroimage and biofeedback technologies increased with the development of IT, and they are now available in cost-effective versions also for the mobile use. EEG (Electroencephalography) technology or fNIRS (Functional Near-Infrared Spectroscopy) can be combined with the 3D interface and offer the dynamic neuro-activity data from the interaction, which is the indispensable value added in the matter of virtual collaboration.

\section{USABILITY SOFTWARE PLATFORMS}

There are several software technologies available for usability studies. Important factor for choosing of particular software platform is its universality, extensibility and possibility to utilization with other software platforms. In our studies software platform Hypothesis is used for the research of virtual collaboration based on 2D visualizations, e. $g$ graphs, images or interactive maps (Fig. 4 a). Hypothesis is a web based platform for experimental testing, which was designed especially for the assessment of map usability. Detail description of this software, its parameters and technological background can be found e.g. in Sterba et al. (2015). Hypothesis offers possibilities to combine quantitative and qualitative research methods. Extensibility and utilization of Hypothesis platform with example in the collection and analysis of eye-tracking data is described by Popelka et al. (2016).

In case of interactive immersive $3 \mathrm{D}$ visualizations, VRECKO and Unity 3D are used. VRECKO software system is an opensource modular software, which has been since 2003 continuously developed by the Human-Computer Interaction 
(HCI) Laboratory at the Faculty of Informatics, Masaryk University. VRECKO is programmed in $\mathrm{C}++$ using the OpenSceneGraph library. A set of modules for visualization of geographical data was created specifically for these studies (Kovalcik et al., 2012; Sprinarova et al., 2015). VRECKO supports different HCI devices (3D mouse, Wii RC) and pseudo 3D and real 3D (stereoscopic) projection (for more details see http://vrecko.cz). VRECKO is currently applicable for providing only individual task solving or direct cooperation of users (see Fig. 4 b), on-line virtual collaboration via internet is not supported. For this purpose (see Fig. 4 c) we start using Unity 3D engine. Unity 3D is originally cross-platform game engine developed by Unity Technologies. Unity supports visualization through Oculus Rift. It can also be used for virtual collaboration with spatial data and networking thanks to the multiplayer mode support.

\section{PROPOSAL OF UTILIZATION OF TECHNOLOGIES}

It is necessary to emphasize, that the most important possibility of mentioned technologies is to combine them and set the adequate interface (examples are shown in Fig. 4) for the fluent and natural interaction as well as for the precise measurement. The interface should by always designed with respect to the purpose of the study, if possible representing all the features as the real environment, but also regarding availability and userfriendliness of used technology. MUVEs represent very specific type of environment. Based on our previous research activities (Sprinarova et al., 2015) we discuss the optimal interface setting for its further development and research. For the interaction with virtual environment, Torres et al. (2013) suggested using 3D glasses as user-friendly device due to immersive aspects of high 3D sensation, low price and practical use, which was also evaluated by participants as very effective within our study (Sprinarova et al., 2015). The current 3D glasses could be combined with the mobile eye-tracking device to detect exact spot of interests on the wide 3D screen. The use of headmounted display is still ambiguous. Although the eyemovement can be measured in head-mounted display too, the sickness and motor confusion when using this technology is still the issue for future research and development, although the use of this device in the virtual space we find as the promising area of virtual collaboration. The optimal control device connected with motor activity measuring tool demands the combination of tracking system and the active-button device (Sprinarova et al., 2015). Motion capture system is the state of the art for humancomputer interaction because of its precision and recording options. Combined with the Wii RC as the active-button (Sprinarova et al., 2015) it is suggested to become user-friendly device for the human-computer interaction.
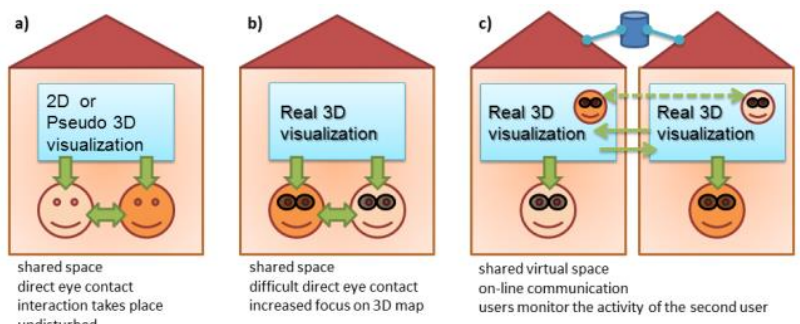

Fig. 4. Different possibilities of utilization of available technologies for collaboration in 3D virtual space

User's behavioral activity during controlling an interface can be effectively measured and at the same time, the user's motor activity and freedom of movement is not limited by the MoCap design. The importance of MoCap increases within the virtual collaboration issue primarily with respect to the possibility to generate active body-based virtual avatar in the MUVEs. This technology is able to create skeleton of the user and transfer it to the virtual environment. For the virtual collaboration the social aspects of interaction and other phenomena such as Proteus Effect (Yee and Bailenson, 2007) are important topics to be considered. For a detailed interpretation of the interaction with $3 \mathrm{D}$ visualization, we recommend user logging. It is suitable to record the particular changes to the position and orientation of a virtual camera (as virtual movement) and all user actions (e.g. pressed buttons). All three mentioned software platforms (Hypothesis, VRECKO and Unity 3D) allows this option.

\section{SUGGESTIONS AND OUTLOOK}

Despite above discussed theories, technologies available, possibilities of connection and pilot testing, current research focused on collaboration within virtual 3D environments constitutes many open issues and problems to be solved. The crucial challenge is dealing both the methodological questions but also with many technological issues. Within our research activities as the first step it is necessary to implement and verify the fluent networking of both our laboratories which are equipped for immersive 3D visualization and interaction with spatial data (Faculty of Arts and Faculty of Informatics). It is also necessary to extend and stabilize the software platforms to enable communication and enhance possible activities of collaborating users. Avatars controlled by MoCap or foveation (explained in: Bektas et al., 2015) controlled by eye-tracking system can be used for this purpose. It will be also necessary to make adjustments that will allow automated processing of users' interaction recording, and further optimization and synchronization of records from multiple devices (MoCap, mobile eye-tracking, EEG etc.) for easier evaluation of results e.g. users strategies. Finally, it will also be necessary to design and test special metrics for users interaction in virtual environments and choose statistical apparatus, which will be suitable for maintained research.

In this paper we suggested the possibilities of establishing the variable platform for the research of virtual work and collaboration. Many of the theoretical, technological and methodological aspects still remain to be explored and precisely defined for the usability research of 3D virtual environments. The influence of the modern technology on the human cognitive processing still remain kind of unclear and in many cases also ambiguous. Either way, the application potential in applied areas underlines the necessity of the research of virtual collaboration as well as the research of individual cognitive processes standing behind virtual environment collaboration and human-computer interaction in general.

\section{ACKNOWLEDGEMENTS}

This research was funded by Grant No. MUNI/M/0846/2015, "Influence of cartographic visualization methods on the success of solving practical and educational spatial tasks" and Grant No. MUNI/A/1315/2015, "Integrated research on environmental changes in the landscape sphere of Earth", both awarded by Masaryk University, Czech Republic. 


\section{REFERENCES}

Anderson, M. L. (2003). Embodied cognition: a field guide. Artificial Intelligence. 149(1) Elsevier, 2003: 91-130.

Bailenson, J., Yee, N., Merget, D., \& Schroeder, R. (2006). The Effect of Behavioral Realism and Form Realism of Real-Time Avatar Faces on Verbal Disclosure, Nonverbal Disclosure, Emotion Recognition, and Copresence in Dyadic Interaction. Presence: Teleoperators And Virtual Environments, 15(4): 359372 .

Bakker, A. B., Albrecht, S. L., Leiter, M. P. (2011). Key questions regarding work engagement. European Journal of Work \& Organizational Psychology, 20(1): 4-28.

Bandrova, T., Zlatanova, S., Konecny, M. (2012). ThreeDimensional Maps for Disaster Management. In: ISPRS Annals of the Photogrammetry, Remote Sensing and Spatial Information Sciences, Vol. I-4. Melbourne, Australia, pp. 245250 .

Barab, S., Thomas, M., Dodge, T., Carteaux, R., Tuzun, H. (2005). Making learning fun: Quest Atlantis, a game without guns. ETR\&D, 53(1): 86-107.

Bektas, K., Cöltekin, A., Krüger, J., Duchowski, A.T. (2015) A Testbed Combining Visual Perception Models for Geographic Gaze Contingent Displays. In: J. Kennedy J., Puppo, E. (eds.) Proceedings of the Eurographics Conference on Visualization, EuroVis 2015.

Bertin, J. (1967). Semiology of Graphics: Diagrams, Networks, Maps. Esri Press; 1st ed. (November 1, 2010).

Biocca, F., Harms, C., Burgoon, J. K. (2003). Toward a more robust theory and measure of social presence: review and suggested criteria. Presence: Teleoperators \& Virtual Environments, 12(5): 456-480.

Björk, S., Holopainen, J. (2004). Patterns In Game Design. Charles River Media.

Boughzala, I., de Vreede, G. J., Limayem, M. (2012). Team Collaboration in Virtual Worlds: Editorial to the Special Issue. Journal of the Association for Information Systems. 13 (Special Issue): 714-734.

Brychtova, A., Popelka, S., Vozenilek, V. (2012). The Analysis of Eye Movement as a Tool for Evaluation of Maps and Graphical Outputs from GIS. In Svobodová H. (ed.), Proceedings of the 19th International Conference on Geography and Geoinformatics: Challenge for Practise and Education. Brno, Czech Republic, pp. 154-162.

Bryson, S. (1999). Virtual Reality: A Definition History, Omnibus Lexicon Definition Supplement. Retrieved from: http://export.arxiv.org/pdf/1312.4322 (2 April 2016).

Csikszentmihalyi, M. (1990). Flow. New York: Harper \& Row.

Dalgarno, B., Lee, M. J. W., Carlson, L., Gregory, S., Tynan, B. (2011). An Australian and New Zealand scoping study on the use of 3D immersive virtual worlds in higher education. Australasian Journal of Educational Technology, 27(1): 1-15.

Davis, A., Murphy, J., Owens, D., Khazanchi, D., Zigurs, I. (2009). Avatars, people, and virtual worlds: Foundations for research in metaverses. Journal of the Association for Information Systems, 10(2): 90-117.
Dennis, A. R., Fuller, R. M., Valacich, J. S. (2008). Media, tasks, and communication processes: A theory of media synchronicity. MIS Quarterly, 32(3): 575-600.

Endsley, M. R. (1995). Measurement of situation awareness in dynamic systems. Human Factors.(37): 32-64.

Forsell, C. (2007). Perceptually Motivated Constraints on $3 D$ Visualizations. PhD dissertation, Uppsala University.

Goel, L., Prokopec, S. (2009). The socialness of virtual worlds. AMCIS 2009 Proceedings. Retrieved from http://aisel.aisnet.org/amcis2009/385 (4 April 2016).

Greiner, B., Caravella, M., Roth, A. E. (2014). Is avatar-toavatar communication as effective as face-to-face communication? An Ultimatum Game experiment in First and Second Life. Journal of Economic Behavior \& Organization, 108: 374-382.

Hammond, K. Stewart, T. (2001). The essential Brunswik. Oxford: Oxford University Press.

Hassell, M., Limayem, M. (2010). Working in the new way: A preliminary study of media synchronicity and job satisfaction. In: AMCIS 2010 Proceedings. Retrieved from: http://aisel.aisnet.org/amcis2010/566 (5 April 2016).

Häberling, C., Bär, H., Hurni, L. (2008). Proposed Cartographic Design Principles for 3D Maps: A Contribution to an Extended Cartographic Theory. Cartographica, 43(3): 175-188.

Herman, L., Reznik, T. (2013). Web 3D Visualization of Noise Mapping for Extended INSPIRE Buildings Model. In: Hrebicek, J., Schimak, G., Kubasek, M., Rizzoli, A. E. (eds.) Environmental Software Systems. Fostering Information Sharing, Springer, pp. 414-424.

Herman, L., Reznik, T. (2015). 3D Web Visualization of Environmental Information - Integration of Heterogeneous Data Sources when Providing Navigation and Interaction. In: Mallet C., et al. (eds.) ISPRS Archives of the Photogrammetry, Remote Sensing and Spatial Information Sciences, Vol. XL-3/W3. La Grande Motte, France, pp. 479-485.

Hideyuki, N. (2004). FreeWalk: a social interaction platform for group behaviour in a virtual space. International Journal of Human-Computer Studies, 60(4): 421-454.

Hochmitz, I., Yuviler-Gavish, N. (2011). Physical Fidelity Versus Cognitive Fi- delity Training in Procedural Skills Acquisition. Human Factors: The Journal of the Human Factors and Ergonomics Society, 53(5): 489-501.

Hossain, L. L., Wigand, R. T. (2004). ICT enabled virtual collaboration through trust. Journal of Computer-Mediated Communication, 10(1): 22-31.

Ibáñez, M., Garcia Rueda, J., Maroto, D., Delgado Kloos, C. (2013). Collaborative learning in multi-user virtual environments. Journal of Network and Computer Applications, 36(6): 1566-1576.

Johnson, S., Suriya, C., Seung Won Yoon, S., Berrett, J. V., La Fleur, J. (2002). Team development and group processes of virtual learning teams. Computers \& Education, 39(4): 379-393.

Kolacny, A. (1968). Cartographic Information - A Fundamental Concept and Term in Modern Cartography. The Cartographic Journal, 6(1): 47-49.

Konecny, M. (2011). Cartography: Challenges and Potentials in Virtual Geographic Environments Era. Annals of GIS. 17(3) Taylor \& Francis: 135-146. 
Kovalcik, V., Chmelik, J., Bezdeka, M., Sochor, J. (2012). Virtual reality system as a tool for education. In: 20th International Conference in Central Europe on Computer Graphics, Visualization and Computer Vision, Plzen, Czech Republic, pp. 15-18.

Kubicek, P., Sasinka, C. Stachon, Z. (2014). Selected Cognitive Issues of Positional Uncertainty in Geographical Data. Geografie, 119(1): 67-90.

Kubicek, P., Sasinka, C., Stachon, Z., Sterba, Z., Apeltauer, K., Urbanek, T. (2016). Cartographic Design and Usability of Visual Variables for Linear Features. The Cartographic Journal, 53(1): [in print].

Lange, M., Hjalmarsson, J., Cooper, M., Ynnerman, A., Duong, V. (2003). 3D Visualization and $3 D$ Voice Interaction in Air Traffic Management. SIGGRAD.

Levan, S. K. (2004). Travail collaboratif sur Internet: Concept, méthodes et pratiques des plateaux projet. Paris, France: Vuibert.

Lim, C., Nonis, D., Hedberg, J. (2006). Gaming in a 3D multiuser virtual environment: engaging students in Science lessons. Br J Educ Technol, 37(2): 211-231.

Lin, H., Batty, M., Jørgensen, S., Fu, B., Konecny, M., Voinov, A., Torrens, P., Lu, G., Zhu, A., Wilson, J.P., Gong, J., Kolditz, O., Bandrova, T., Chen, M. (2015). Virtual Environments Begin to Embrace Process-based Geographic Analysis. Transactions In GIS, 19(4): 493-498.

MacEachren, A. M., Kraak, M. J. (2001). Research Challenges in Geovisualization. Cartography and Geographic Information Science, 28(1): 3-12.

Maggi, S., Fabrikant, S. I., Imbert, J.-P., Hurter, C. (2015). How do Display Design and User Characteristics Matter in Animations? An Empirical Study with Air Traffic Control Displays. Cartographica. 51(1): 25-37.

Mania, K., Wooldridge, D., Coxon, M., Robinson, A. (2006). The effect of visual and interaction fidelity on spatial cognition in immersive virtual environments. IEEE Trans. Visual. Comput. Graphics, 12(3): 396-404.

Mania, K., Chalmers, A. (2001). The Effects of Levels of Immersion on Memory and Presence in Virtual Environments: A Reality Centered Approach. Cyber Psychology \& Behavior, 4(2): 247-264.

Meteyard, L., Cuadrado, S. R., Bahrami, B., Vigliocco, G. (2012). Coming of Age: A Review of Embodiment and the Neuroscience of Semantics. Cortex, 48(7): 788-804.

Montoya, M., Massey, A., Lockwood, N. (2011). 3D Collaborative Virtual Environments: Exploring the Link between Collaborative Behaviors and Team Performance. Decision Sciences, 42(2): 451-476.

Neisser, U. (1976). Cognition and Reality: Principles and Implications of Cognitive Psychology. San Francisco: W. H. Freeman \& Company.

Petrakou, A. (2010). Interacting through avatars: Virtual worlds as a context for online education. Computers \& Education, 54(4): 1020-1027.

Plant, K., Stanton, N. (2012). Why did the pilots shut down the wrong engine? Explaining errors in context using Schema Theory and the Perceptual Cycle Model. Safety Science, 50(2): 300-315.
Popelka, S., Vozenilek, V. (2013). Specifying of Requirements for Spatio-Temporal Data in Map by Eye-Tracking and SpaceTime-Cube. In: Zhu, Z. (ed.). International Conference on Graphic and Image Processing (ICGIP 2012), Wuhan, China.

Popelka, S., Stachon, Z., Sasinka, C., Dolezelova, J. (2016). EyeTribe Tracker Data Accuracy Evaluation and Its Interconnection with Hypothesis Software for Cartographic Purposes. Computational Intelligence and Neuroscience. 2016.

Reznik, T. (2013). Geographic information in the age of the INSPIRE Directive: discovery, download and use for geographical research. Geografie, 118(1): 77-93.

Reznik, T., Horakova, B., Szturc, R. (2013). Geographic Information for Command and Control Systems Demonstration of Emergency Support System. In: Zlatanova, S., Dilo, A., Peters, R., Scholten, H. (eds.) Intelligent Systems for Crisis Management: Geo-information for Disaster Management (GI4DM) 2012, Springer, pp. 263-275.

Riedl, R., Mohr, P. N. C., Kenning, P. H., Davis, F. D. Heekeren, H. R. (2014). Trusting Humans and Avatars: A Brain Imaging Study Based on Evolution Theory. Journal of Management Information Systems, 30(4): 83-114.

Rierson, L. (2013). Developing Safety-Critical Software: A Practical Guide for Aviation Software and DO-178C Compliance. New York: CRC Press. 610 p.

Roebuck, K. (2011). 3D Television: High-impact Emerging Technology - What You Need to Know: Definitions, Adoptions, Impact, Benefits, Maturity, Vendors. Tebbo.

Shuman, B. A. (1992). Foundations and Issues in Library and Information Science. Englewood: Libraries Unlimited, 471 p.

Stanek, K., Friedmannova, L., Kubicek, P., Konecny, M. (2010). Selected issues of cartographic communication optimization for emergency centers. International Journal of Digital Earth, 3(4): 310-339.

Slater, M., Wilbur, S. (1997). A framework for immersive virtual environments (FIVE) : Speculations on the role of presence in virtual environments. Presence : Teleoperators and Virtual Environments, 6(6), 603-616.

Sprinarova, K., Jurik, V., Sasinka, C., Herman, L., Sterba, Z., Stachon, Z., Chmelik, J., Kozlikova, B. (2015). Humancomputer Interaction in Real 3D and Pseudo-3D Cartographic Visualization: A Comparative Study. In: Sluter, C. R., et al. (eds.) Cartography - Maps Connecting the World: 27th International Cartographic Conference 2015 - ICC2015. Springer, pp. 59-73.

Sterba, Z., Sasinka, C., Stachon, Z., Stampach, R., Morong, K., (2015). Selected Issues of Experimental testing in Cartography. Masaryk University, MuniPress, Brno.

Tavanti, M., Dang, N. T., Le-Hong. H. (2003): ThreeDimensional Stereoscopic Visualization for Air Traffic Control Interfaces: a Preliminary Study, In: Proceedings of the 22nd AIAA/IEEE Digital Avionics Systems Conference, Indianapolis, Indiana, October, 2003.

Torres, J., Ten, M., Zarzoso, J., Salom, L., Gaitan R., Lluch, J. (2013) Comparative Study of Stereoscopic Techniques Applied to a Virtual Globe. Cartographic Journal. 50(4): 369-375.

Yee, N., Bailenson, J. (2007). The Proteus Effect: The Effect of Transformed Self-Representation on Behavior. Human Communication Research, 33(3): 271-290. 
Waller, D., Knapp, D., Hunt E. (2001). Spatial Representations of Virtual Mazes: The Role of Visual Fidelity and Individual Differences. Human Factors, 43(1): 147-158.

Weinberg, G., Harsham, B., Medenica, Z. (2011). Evaluating the usability of Head-Up Display for Selection from Choice list Cars. Mitsubishi research laboratories: Cambridge. Retrieved from: http://www.merl.com/publications/docs/TR2011-076.pdf (4 April 2016).

Wilson, M. (2002). Six views of embodied cognition. Psychonomic Bulletin \& Review, 9(4): 625-636.

Wilson, C. and Soranzo, A. (2015). The Use of Virtual Reality in Psychology: A Case Study in Visual Perception. Computational and Mathematical Methods in Medicine, pp.1-7.

Zimmerman, J., Koebbe, B. (2013). Flying with the iPad. Sporty's PilotShop. Batavia: $\mathrm{OH}$. 